\title{
Group recruitment in a thermophilic desert ant, Ocymyrmex robustior
}

\author{
Stefan Sommer • Denise Weibel $\cdot$ Nicole Blaser • \\ Anna Furrer · Nadine E. Wenzler • \\ Wolfgang Rössler $\cdot$ Rüdiger Wehner
}

Received: 19 March 2013/Revised: 30 April 2013/Accepted: 17 May 2013/Published online: 8 June 2013

(c) Springer-Verlag Berlin Heidelberg 2013

\begin{abstract}
Thermophilic desert ants-Cataglyphis, Ocymyrmex, and Melophorus species inhabiting the arid zones of the Palaearctic region, southern Africa and central Australia, respectively—are solitary foragers, which have been considered to lack any kind of chemical recruitment. Here we show that besides mainly employing the solitary mode of food retrieval Ocymyrmex robustior regularly exhibits group recruitment to food patches that cannot be exploited individually. Running at high speed to recruitment sites that may be more than $60 \mathrm{~m}$ apart from the nest a leading ant, the recruiter, is followed by a loose and often quite dispersed group of usually 2-7 recruits, which often overtake the leader, or may lose contact, fall back and return to the
\end{abstract}

\section{S. Sommer}

Institute of Evolutionary Biology and Environmental Studies, University of Zürich, Winterthurerstrasse 190, 8057 Zurich,

Switzerland

D. Weibel

EAWAG, Swiss Federal Institute of Aquatic Science and

Technology, Seestrasse 79, 6047 Kastanienbaum, Switzerland

N. Blaser

Institute of Anatomy, University of Zürich,

Winterthurerstrasse 190, 8057 Zurich, Switzerland

\section{A. Furrer}

Kantonsschule Olten, Hardfeldstrasse 53, 4600 Olten, Switzerland

N. E. Wenzler · W. Rössler · R. Wehner Biocenter, University of Würzburg, Am Hubland, 97074 Würzburg, Germany

\section{R. Wehner $(\bowtie)$}

Brain Research Institute, University of Zürich, Winterthurerstrasse 190, 8057 Zurich, Switzerland e-mail: rwehner@zool.uzh.ch nest. As video recordings show the leader, while continually keeping her gaster in a downward position, intermittently touches the surface of the ground with the tip of the gaster most likely depositing a volatile pheromone signal. These recruitment events occur during the entire diurnal activity period of the Ocymyrmex foragers, that is, even at surface temperatures of more than $60{ }^{\circ} \mathrm{C}$. They may provide promising experimental paradigms for studying the interplay of orientation by chemical signals and path integration as well as other visual guidance routines.

Keywords Desert ants - Recruitment - Ocymyrmex . Path integration $\cdot$ Solitary foraging

\section{Introduction}

Thermophilic desert ants of the genera Cataglyphis, Ocymyrmex, and Melophorus, which inhabit the arid zones of the Palaearctic region, southern Africa and central Australia, respectively, are strictly diurnal foragers. They mainly search for carcasses of arthropods, which are widely scattered across the desert floor, and retrieve these food items individually (Harkness and Wehner 1977; Schmid-Hempel 1983; Wehner et al. 1983; Marsh 1985; Wehner 1987; Lenoir et al. 1990; Cerdá et al. 1998; Muser et al. 2005; Schultheiss et al. 2013). In fact, in the natural habitat of Cataglyphis bicolor, in which the foraging ecology of these thermophilic scavengers has been studied most intensively, clumped food patches do rarely occur. Moreover, if aggregated and homogeneous food distributions are generated experimentally within the ants' natural habitat, colonies of $C$. bicolor are more efficient in retrieving food items from the latter rather than the former distribution (Schmid-Hempel 1983). 
Even though during the course of their foraging lives individual workers tend to develop quite persistent sector fidelities - that is, ants concentrate their searches on particular club-shaped areas of the colony's foraging territory (Wehner 1987; Wehner et al. 2004)—within such foraging sectors workers do usually not search thoroughly at the place where they have found food on the preceding foraging trip. Most foragers move over extended areas and rarely if ever concentrate their searches on one place; rather they usually pass their previous finding sites and move farther outwards. Only if highly rewarding food patches are established experimentally within the workers' foraging sectors (as usually done during training experiments performed in the context of studies on the ants' navigational toolkit), do individual ants repeatedly return to that patch. However, even under these special conditions each forager remains an individual exploiter. In several Cataglyphis species quite some efforts have been made to elicit recruitment to experimentally established rich and renewable food sites, but never could such co-operative behaviour be observed (Schmid-Hempel 1983; Wehner et al. 1983; Lenoir et al. 1990; for M. bagoti, see Muser et al. 2005). In all cases did the number of foragers arriving at those sites for the first time (newcomers) increase linearly rather than exponentially over time. This constant rate of newcomer arrivals is in accord with the hypothesis that all workers appearing at a rich food patch-in our case at an experimentally established feeding station-have encountered that site individually rather than by group processes. Moreover, model calculations show that the number of ants arriving at the feeding station is completely in accord with the predicted number of ants finding the bait by chance during their usual solitary foraging journeys (Schmid-Hempel 1983).

This failure to demonstrate any kind of chemical recruitment to distant food sources in the strictly thermophilic Cataglyphis species is in accord with the generally held view that the various mechanisms by which individual ants join their efforts in food retrieval are strongly correlated with the spatial and temporal food distributions prevailing within the foraging range of the colony, with colony size, population structure, etc. (Hölldobler and Lumsden 1980; Hölldobler and Wilson 1990). This view is based on a multitude of experimental studies in a large number of species, starting with Edward O. Wilson's seminal work on chemical mass communication in the red imported fire ant (Solenopsis invicta [saevissima]; Wilson 1962), which is endowed with an extremely complex multicomponent chemical trail system (Vander Meer 1986), and culminating in Bert Hölldobler's detailed analyses of various evolutionary grades of recruitment communication in ponerine, myrmicine, and formicine species (for reviews, see Hölldobler 1981b, 1984; Hölldobler and Wilson 2009).
Seen in the light of these comparative analyses, thermophilic scavengers represent the hallmark of the solitary mode of foraging. Moreover, in a survey of 50 diurnally foraging species of myrmicines and formicines Ruano et al. (2000) have classified foraging strategies into two categories. Based on the data about maximal soil-surface temperatures during the ants' activity periods and the ants' mode of foraging (recruitment-based or solitary), they conclude that species that are active at lower temperatures use chemical signals to recruit nest mates during foraging, while those being active at high temperatures do not, and exclusively employ solitary modes of foraging. In the latter category Cataglyphis, Melophorus, and Ocymyrmex species are listed as prime examples. The authors' main argument for why ants foraging at high temperatures do not recruit is that under these conditions the highly volatile recruitment pheromones would be inefficient signals, so that in thermophilic species a strong selection pressure should have acted against their costly production (Ruano et al. 2000).

All the more have we been excited by observing an 'elementary' but rather common kind of apparently chemical recruitment in Ocymyrmex, the ecological counterpart of Cataglyphis in southern Africa. Actually, it was already in our first study of the foraging and orientation behaviour of ants of that genus, the large-sized $O$. velox in the gravel plains north of the Kuiseb River in Namibia (in 1983), that we discovered individual ants recruiting small, loosely aggregated groups of 5-10 workers to patches of harvester termites, when these slowly moving, soft-bodied insects had occasionally appeared foraging above ground (Wehner 1987). In the meantime we have regularly observed this recruitment phenomenon to isolated food patches in $O$. velox, and in $O$. robustior (then still subsumed under $O$. barbiger; see Marsh 1985) as well.

In the present account we first describe general aspects of the solitary foraging behaviour of $O$. robustior. We then focus on the ants' recruitment behaviour, especially its spatial and temporal characteristics. Finally, we concentrate on the behaviour of the recruits and ask whether this behaviour could provide an experimental paradigm to test the hypothesis that path integration, the desert ants' principal means of navigation, is an inborn routine operating already during the workers' first outdoor journeys.

\section{Methods}

Observations and experiments on $O$. robustior foragers were done in the dry upper-level riverbed of the Kuiseb River near the Gobabeb Training and Research Centre $\left(23^{\circ} 34^{\prime} \mathrm{S}, 15^{\circ} 03^{\prime} \mathrm{E}\right)$ in the Namib-Naukluft Park, Namibia. The Kuiseb River, an ephemeral river separating the gravel plains in the north from the great Sand Dunes Sea in the 
south, forms a linear oasis with extended sandflats in the centre and bushes (e.g., Salvadora persica, the Mustard bush) and trees on the river banks (predominantly Acacia erioloba, Camel Thorn, Faidherbia albida, Ana Tree, and Tamarix usneoides, Wild Tamarix) (Theron et al. 1980; Mizuno 2010; Schachtschneider and February 2010). The colonies of $O$. robustior investigated in the present account were located on the bare sandflats. The foraging activity of this species, including recruitment behaviour, was studied systematically during four seasons-from July to September 2003, from January to March 2005, from January to February 2006, and from November to December 2009.

\section{General foraging activity}

We recorded the daily foraging activity by counting the number of ants leaving the nest during 5-min periods at 30-min intervals. An ant was considered to start foraging when it crossed a circle with a radius of $0.4 \mathrm{~m}$ drawn around the nest-entrance hole. The circle was divided into twelve $30^{\circ}$ sectors to record the ants' foraging directions. We further measured soil-surface temperatures every half an hour using a copper-constantan thermocouple connected to a digital thermometer (Physitemp BAT-12, Physitemp Instruments, Inc., Clifton, New Jersey; for a detailed description of the method used to measure soilsurface temperature, see Wehner and Wehner 2011).

We marked all newly emerging foragers with day-specific two-colour codes by applying dots of acrylic paint (Dupli-Color, Hassersheim, Germany) on the ants' gaster and alitrunk. To trace individual ants on several foraging runs, we applied ant-specific colour codes. This marking procedure enabled us to identify individual foragers and to distinguish between experienced (marked) and inexperienced (unmarked) ants participating in any given recruitment event. After an initial marking period of 3 days, all unmarked foragers were considered inexperienced. However, complete activity protocols of cohorts of individually marked ants over extended periods of time have still to be established. For each recruitment event we recorded the time of day and the numbers of experienced and inexperienced ants. The day-specific colour codes enabled us to determine the (foraging) age of recruiter and recruits; unmarked ants were inexperienced and, by definition, first-day foragers.

\section{Spatial layout of runs}

The runs of individually marked foragers were traced by placing numbered flags on the ants' tracks at 30-s intervals. Foraging direction was recorded to the nearest $5^{\circ}$ at a distance of $4 \mathrm{~m}$ from the nest-entrance hole. When a recruitment event was initiated, one person followed the recruiter (the leading ant), while another person observed a recruit (a led ant); a third person continued to monitor the foraging activity at the nest entrance. The spatial layout of the runs of recruiter and recruit were recorded by placing numbered flags on the ants' tracks at 10-s intervals (roughly every 1-4 m, depending on the ants' running speed). Since it took the observer(s) some time to identify a recruitment event-and the recruiting ant-as such, the recordings of outbound (nest-to-food item) runs did not start directly at the nest-entrance hole. The food items were flagged - if relocated by the recruiter-and food items were identified. At the end of each day, after the foraging activity had ceased, the coordinates of all flagged positions were determined using differential GPS (Ashtech ${ }^{\circledR}$ ProMark $^{\mathrm{TM}}$ Survey System, Thales Navigation, Santa Clara, California). The spatial layout of the ants' trajectories were later analysed using ArcView ${ }^{\circledR}$ GIS 3.3.

In addition, video analyses were used to record the walking trajectories of recruiters and recruits at a much smaller spatial scale. In these cases recruitment behaviour was elicited by installing artificial food sources (small piles of biscuit crumbs soaked in tuna oil) to the north, east, west, and northwest of the nest entrance at a distance of $4 \mathrm{~m}$. This 4-m distance corresponded to the maximal recording distance of a stationary camera that was placed above the nest entrance. The camera (Panasonic HDC SD300 Camcorder; Panasonic Marketing Europe $\mathrm{GmbH}$, Wiesbaden, Germany) was mounted on a tripod (Manfrotto; Imaging One $\mathrm{GmbH}$, Lübeck, Germany) with a pivoting centre column. We used a B+W $43 \mathrm{~mm}$ circular polarizer (Digital Pro) to minimise reflections of the sand surface. The cameracovered with an overhead shield to keep temperatures below $40{ }^{\circ} \mathrm{C}$ - was installed at an inclination of $90^{\circ}$ with the centre column aligned over the nest-entrance hole. A circle with a radius of $0.4 \mathrm{~m}$ drawn around the nest entrance served as a scale for distance measurements.

For the analyses of individual tracks the videos (m2ts files) were converted to avi files using Panasonic software HD Writer AE 1.0 (BIT-4U, Schneverdingen, Germany) and VirtualDubMod 1.5.10.2 software (Softsonic, Barcelona, Spain). We used Fidji-win32 software (Wayne Rasband, National Institute of Health, USA) to mark individual ants in image sequences of avi files and to create overlays of processed images. Path lengths and distances between ants were measured in CorelDraw X3 (Corel Corporation, Ottawa, Canada).

\section{Results}

General foraging activity

On the sandflats of the upper-level riverbed of the Kuiseb River the colonies of $O$. robustior were located usually on 
(a)

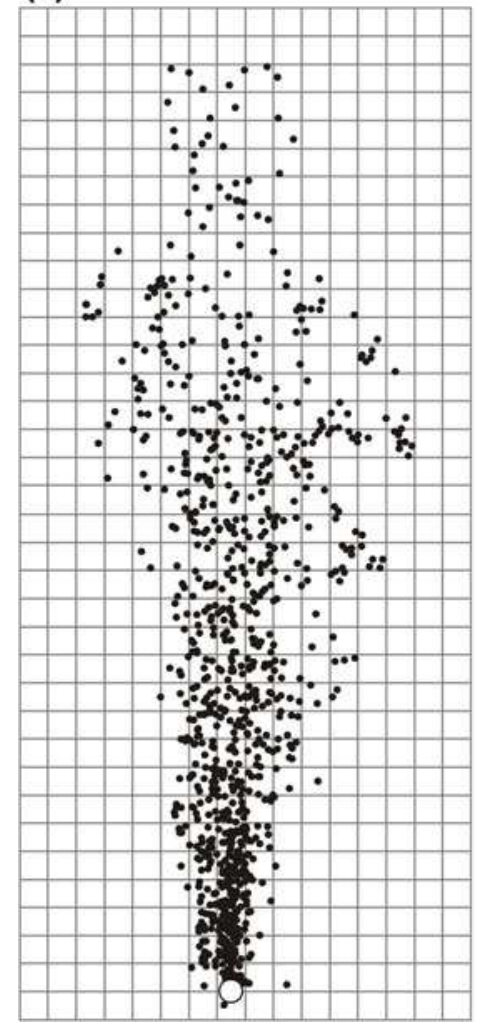

(b)
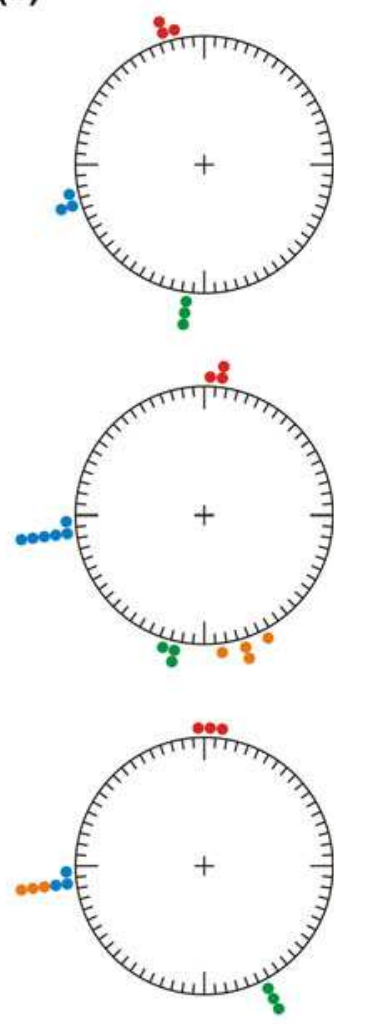

Fig. 1 Spatial layout of foraging runs. a Shown are 32 foraging runs of 25 ants from three different nests. Dots represent the ants' positions at 30 -sec intervals; grid size is $2 \mathrm{~m}$. Runs are rotated to superimpose mean foraging directions. b Foraging directions of individual ants (represented by different colours) at three nests. Running directions (dots) are measured at $4 \mathrm{~m}$ from the nest-entrance hole (cross)

barren ground, but often close to stones or tussocks of driedout grass, Cladoraphis spinosa, and less frequently close to bushes (usually Salvadora persica) or trees on the river banks (predominantly Acacia erioloba). In total 54 nests were found and mapped within the study area of $60^{\prime} 773 \mathrm{~m}^{2}$. A nearest-neighbour analysis (Clark and Evans 1954) revealed a non-random distribution $(R=1.323)$ with a tendency towards a regular (overdispersed, indicated by $R>1)$ rather than a clumped pattern $(R<1)$, and a nearestneighbour distance of $22 \mathrm{~m}$. As the mean foraging distance-that is, the distance between the nest and an individually encountered and retrieved food item-amounted to $31.0 \mathrm{~m} \pm 16.9 \mathrm{~m}$ (mean $\pm \mathrm{SD}$; mean foraging time, $19.6 \mathrm{~min} \pm 15.1 \mathrm{~min} ; n=93$ ), there was a considerable overlap between the foraging ranges of adjacent nests.

Individual workers were bound to spatially limited, rather narrow, club-shaped foraging ranges (Fig. 1a). They often ran straight to a particular area, especially when this was close to a tree or bush at the fringes of the riverbed, and exhibited more convoluted search trajectories only there. While different ants from the same colony searched in different directions (Figs. 1b, 2), individual ants rather persistently stuck to their individual (preferred) foraging directions (Fig. 1b).

Foraging activity was confined to daytime hours. At our study site it occurred all year round, but was strongly dependent on ambient temperature. In the late-summer period (between 24 January and 26 March 2005) during which recordings of recruitment events were done most comprehensively, the ants' foraging activity exhibited a bimodal distribution with a small and a high peak in the morning and the afternoon, respectively (Fig. 3). The ants stopped foraging only when surface temperatures exceeded $67{ }^{\circ} \mathrm{C}$ (for a detailed discussion of temporal foraging patterns and their temperature relations, see Wehner and Wehner 2011).

\section{Recruitment behaviour}

Every now and then a forager, which had discovered a rich food source (e.g., a site at which live harvester termites, Hodotermes mossambicus, had appeared above ground, or at which berries or lepidopteran larvae occurred), started to recruit some nest mates to that site. As with individual foraging this kind of co-operative food retrieval occurred in various directions from the nest and over quite large distances (up to more than $60 \mathrm{~m}$; Fig. 4). The temporal distribution of recruitment events closely matched the pattern of the ants' daily foraging activity (Fig. 3) demonstrating that these events were not restricted to lower temperature regimes. We counted a total of 64 recruitment events in the course of 37 observation days (i.e., 1.7 recruitments per day; range $0-7$ recruitments per day). In 37 cases we could locate the target (food item) of the recruiting ants. The majority of these runs were directed towards living termites (26\%), dead insects (24\%), and berries (22\%); the remaining targets included dead caterpillars and miscellaneous food items (14\% each).

Inside the nest the ant having returned from the food site obviously initiated a recruitment process, which resulted in an outburst of a small group of heavily agitated nest mates. The recruited ants gathered for some time close to the nest entrance where they gave the impression of a small cloud of black dots wildly whirling around the recruiter, with which they tried to get in tactile contact, but which at this stage of the recruitment process was sometimes difficult to locate. Starting slowly and spatially compact in the initial phase, this cloud soon got elongated, gained speed, and took off in one direction. By now the leading ant could be easily identified as the ant running straight ahead. The recruits followed behind darting wildly and looping sideways rather than proceeding along a straight path (Fig. 5). In trying to keep up with the leading ant they performed alternating turns of various sizes and by this regularly 
Fig. 2 Foraging trajectories of ants from two nests. Paths of individual foragers (colours) were recorded $\mathbf{a}$ in July and August 2003 (the insets show outbound directions recorded over $70 \mathrm{~min} ; n=209)$ and $\mathbf{b}$ in September 2003 (60 min; $n=258)$. Lines converge at the nest-entrance hole; circles represent the outlines of treetops and bushes. Trajectories close to trees are slightly distorted, since the GPS did not receive signals under trees

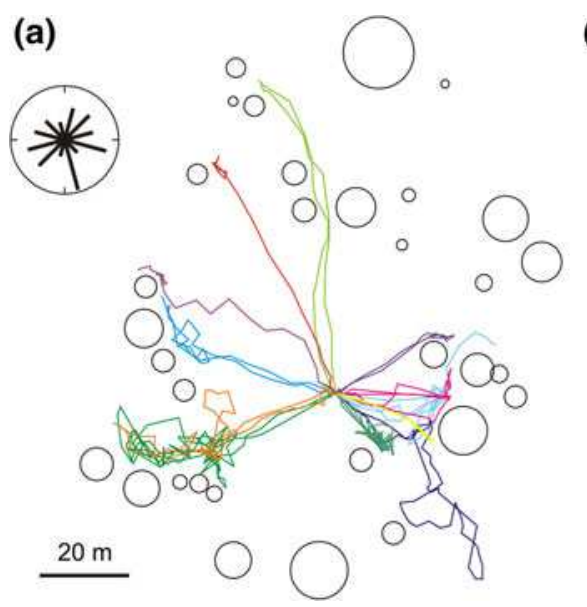

(b)

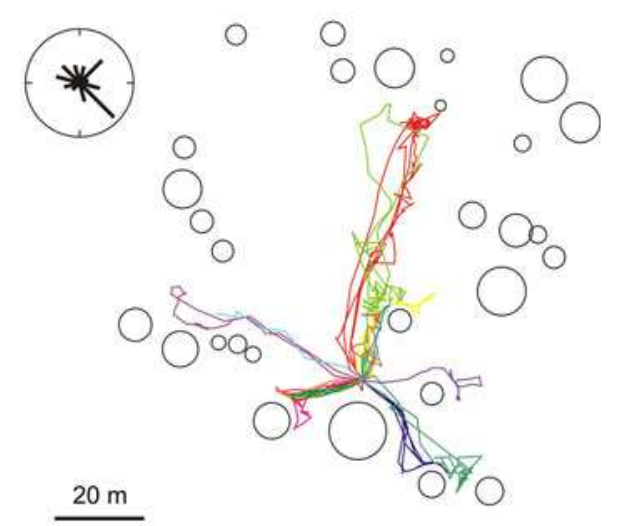

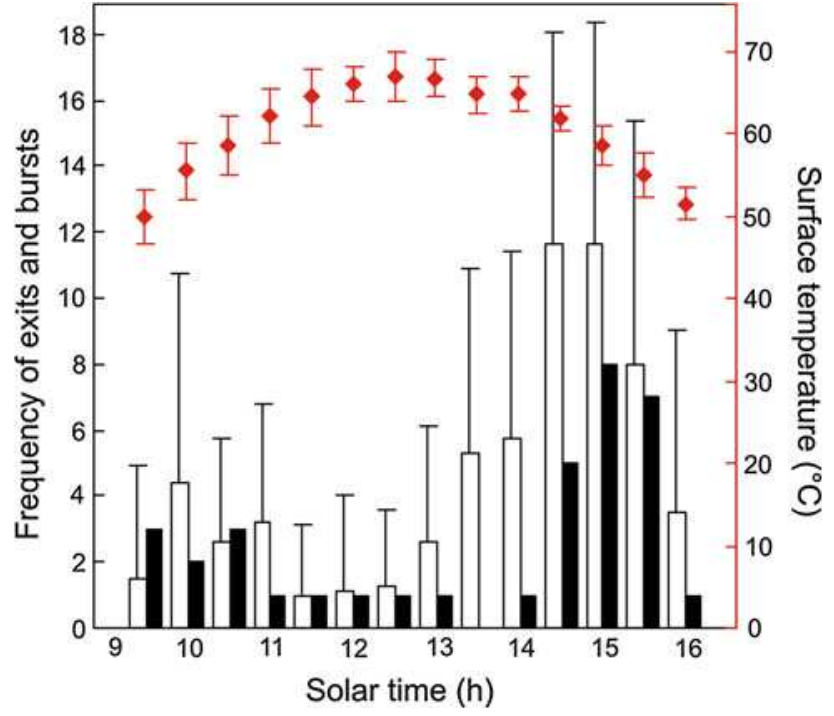

Fig. 3 Daily foraging activity. Shown are the frequencies of outbound runs of individual foragers (white histograms, mean $\pm \mathrm{SD}$ ) and bursts (group-foraging events; black histograms, total numbers), along with soil-surface temperatures (red symbols, mean $\pm \mathrm{SD}$ ), recorded at a single nest on 21 days between 22 February and 19 March 2005

crossed the leader's former path, but often fell far behind. During this sideways darting behaviour they occasionally got lost and returned to the nest. On the other hand, in their wild hunt in pursuit of the leading ant the recruits often overtook the leader and got ahead of her (Fig. 6).

In spite of the rapid and often quite erratic looping behaviour of the recruits, in the end the recruiting process could be quite successful in finally leading a large fraction of the following ants even over quite large recruitment distances (Fig. 4). Artificial food sources established at a 4-m distance from the nest were finally encountered by all recruited ants. How the success rate depends on recruitment distance, on type of food source and the odour plume

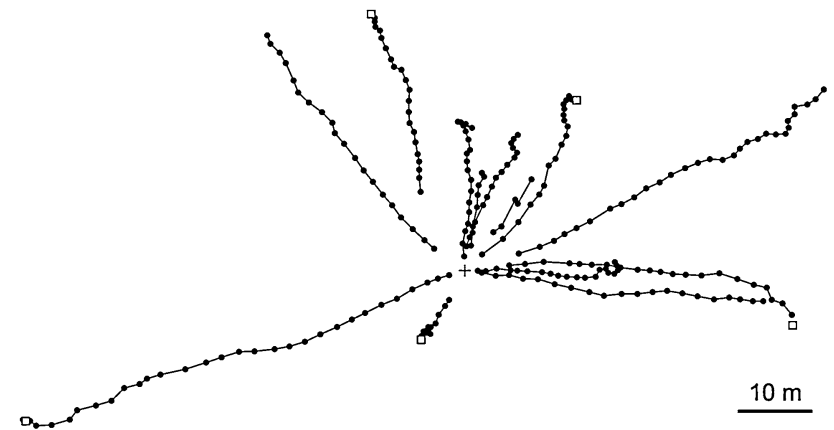

Fig. 4 Trajectories of recruiting ants. Shown are the outbound runs of 13 recruiters, recorded on different days at a single nest; the cross indicates the nest entrance. Dots mark the ants' positions at 10-sec intervals; open squares denote locations of food items

emanating from it, on experience of the recruits, and on other factors remains to be elucidated.

How does the leading ant guide her followers? Even with the naked eye one could observe that the recruiter kept her gaster in a downward position and repeatedly touched the surface of the ground with the tip of the gaster (probably depositing a pheromone signpost). Video recordings revealed the details (Fig. 7). While indeed keeping her gaster continually in a lowered position, the recruiting ant intermittently - at least once per second - dipped the tip of the gaster on to the ground. In contrast, the recruits held their gaster in an elevated position. The video recordings also enabled us to reconstruct the details of the initial phase of the recruitment process as described above (Fig. 5).

At this juncture let us mention two isolated observations. First, in a few pilot experiments an artificial trail consisting of some droplets of poison gland extract (applied with a syringe to ensure equal application) was laid from the nest entrance for a distance of $0.2 \mathrm{~m}$. In one case an outburst with one recruiter and five followers occurred shortly $(65 \mathrm{~s})$ after the trail had been applied. The recruiter's trajectory deviated from the artificial trail by about $60^{\circ}$. One recruit followed the 
Fig. 5 Trajectories of recruiting and recruited ants. Shown are the outbound runs of ants from three recruitment events involving a leader (heavy black line) and $\mathbf{a}, \mathbf{b}$ four and c seven followers. Different colours represent runs of different recruits; the cross marks the nest entrance (a)

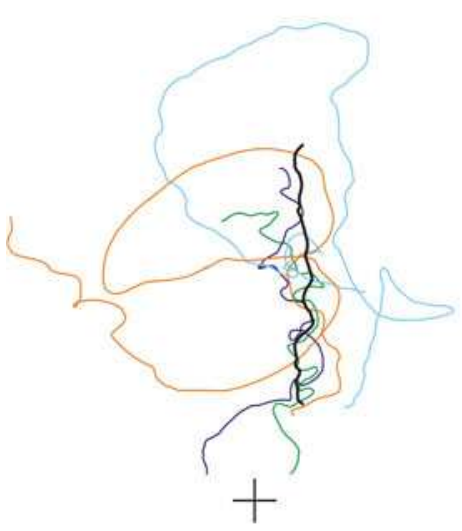

$10 \mathrm{~cm}$ (b)

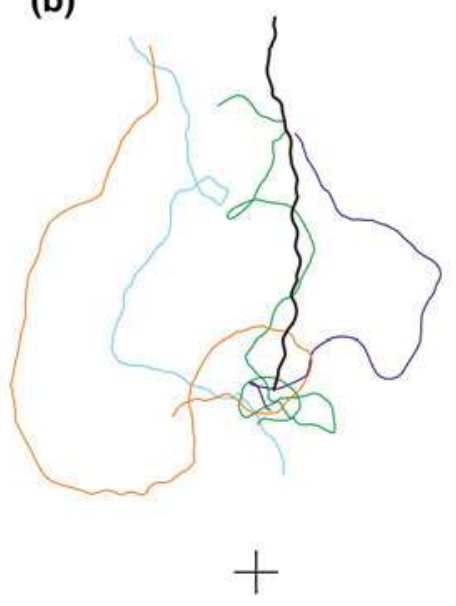

(c)

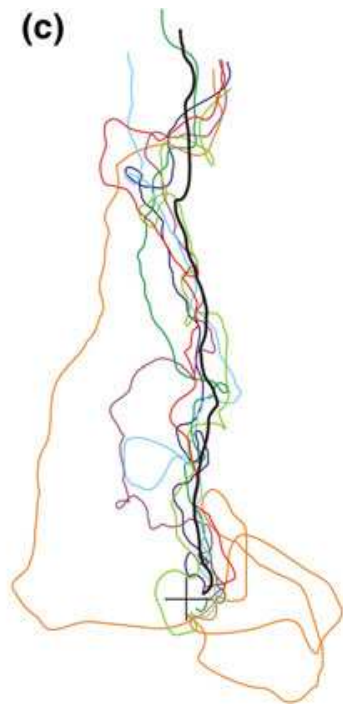

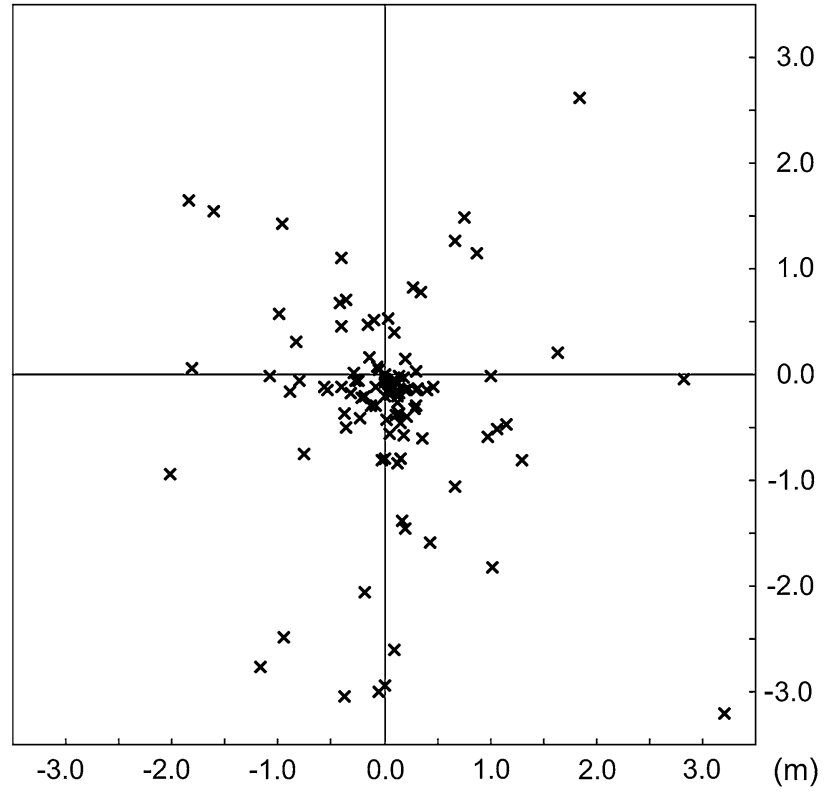

Fig. 6 Positions of recruits relative to the recruiter. Crosses indicate the locations $(n=105)$ of 10 recruited ants relative to the position of the recruiter (at the intersection of the $x$ - and the $y$-axis); the running direction of the recruiter points upwards

former, and another the latter, both sinusoidally looping around the trail. The remaining three recruits were obviously undecided and returned to the nest. Second, in one instance, some kind of follow-behind behaviour was observed. In this case only one nest mate was recruited, which followed directly behind the leader and did not engage in the otherwise usual erratic circling and sideways darting movements. As these encounters were not video recorded, the details of this follow-behind behaviour could not be unravelled. For example, it could not be decided whether the follower kept antennal contact with the leading ant.
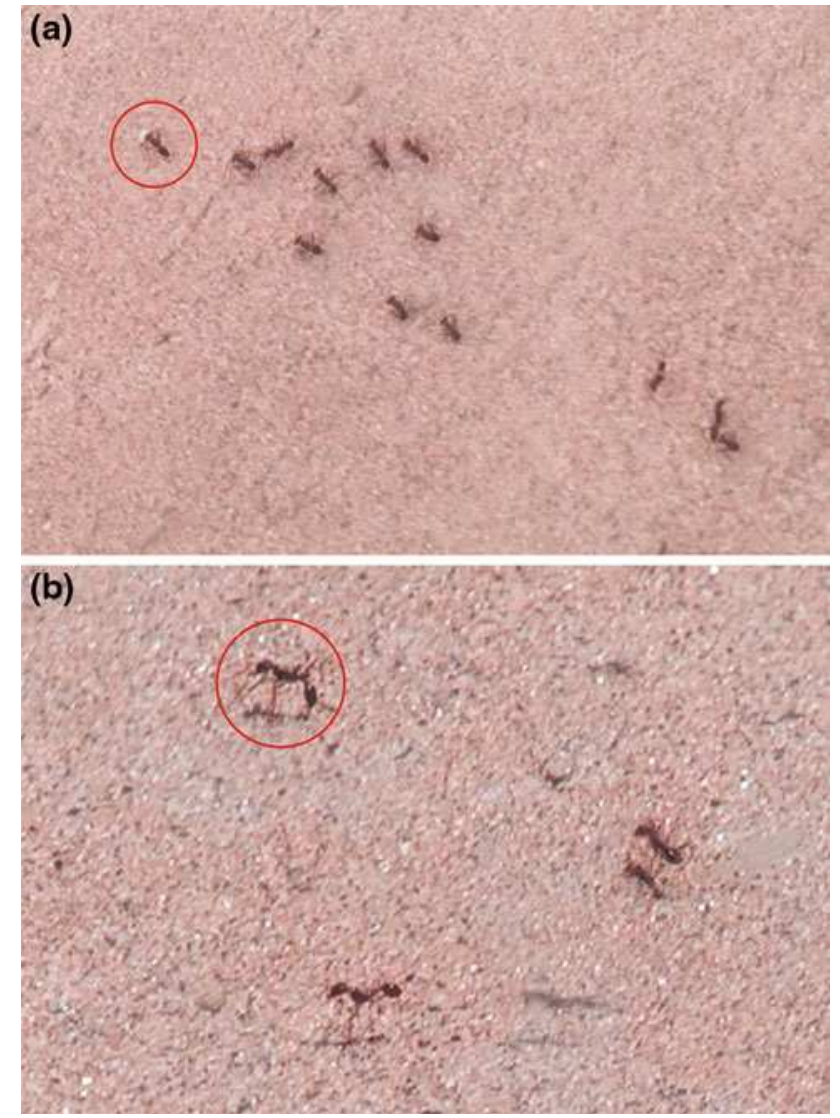

Fig. 7 Recruitment behaviour in O. robustior. a The recruiter (encircled) leads recruits to a previously detected food item. b During the outbound run the recruiter (encircled) repeatedly touches the ground with the gaster

Over a period of 39 days we marked on average 23 new foragers per day (range 1-96 ants) at a single nest. Based on these initial markings and the counting of all foragers on a particular day we estimated the forager force at this nest 
to consist of roughly 100 ants. That is, approximately onefourth of the forager force was replaced each day. This estimate is in good agreement with the ratio of experienced to inexperienced ants participating in recruitment events. In 64 events analysed, $2.4 \pm 1.8$ (mean $\pm \mathrm{SD}$; range 1-13) experienced and $0.8 \pm 1.0(0-5)$ inexperienced recruits followed the recruiting ant. The recruiter was on average older (mean foraging age $\pm \mathrm{SD}, 12.3$ days \pm 7.5 days; $n=43$ ) than the experienced recruits (mean foraging age $\pm \mathrm{SD}, 7.4$ days \pm 6.0 days; $n=128$ ); inexperienced recruits were by definition $<1$ foraging day old.

Does participation in a recruitment event mark the start of an ant's foraging live, and if so, does it determine the ant's future foraging direction? On average, we observed 1.7 recruitment events per day with a mean value of 0.8 inexperienced recruits participating per event. That is, on average, only 1.4 ants out of $23(6 \%)$ new foragers per day started their foraging lives as a recruit, whereas $94 \%$ of ants started foraging individually. However, 5 out of 8 ants we initially observed as inexperienced recruits and later as individual foragers chose a foraging direction during their first individual run that was within $40^{\circ}$ from the direction of recruitment.

The observation described above that ants, which were considered inexperienced-that is, which had not yet started their foraging lives-could get recruited over quite large distances might offer a unique possibility to study the onset of the path integration process in newly emerging foragers. These "newcomers" indeed returned home along rather straight paths, and did so neither along their own outbound path, nor along the outbound path or inbound path of the recruiter (Fig. 8). In quantitative terms, the homing directions of recruiters and experienced as well as inexperienced recruits scattered around the true homing direction and did not differ statistically from the latter course $(95 \%$ confidence intervals: recruiters, [356.43 , $\left.3.71^{\circ}\right], n=29$; experienced recruits, $\left[357.24^{\circ}, 4.91^{\circ}\right.$ ], $n=23$; inexperienced recruits, $\left[359.98^{\circ}, 6.11^{\circ}\right], n=21$ ). Moreover, pair-wise comparisons (Watson-Williams test, Batschelet 1981) did not reveal any statistical differences in the homing error, measured as absolute deviation of each ant's homing course from $0^{\circ}$, between the three groups of ants (all $p$ values $>0.2$ ). Of course, displacement experiments should be performed to finally test the hypothesis that the recruits, be they experienced or inexperienced foragers, home by path integration or other visual rather than olfactory guidance regimes.

\section{Discussion}

The foraging pattern of any ant species depends on the nutritional demands of the colony and the spatial and

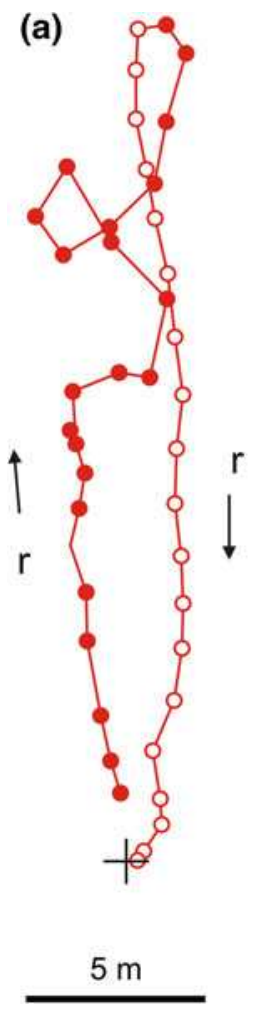

(b)

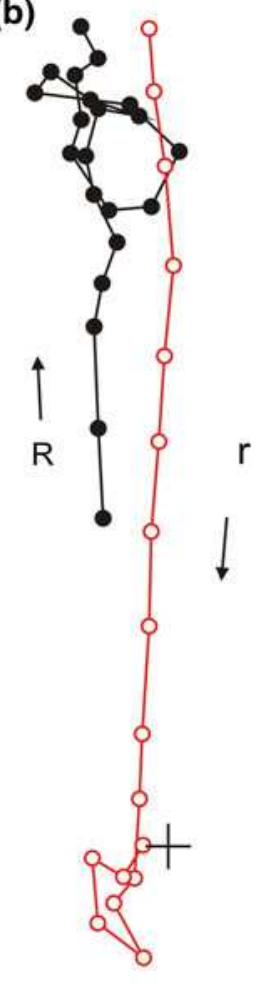

(c)

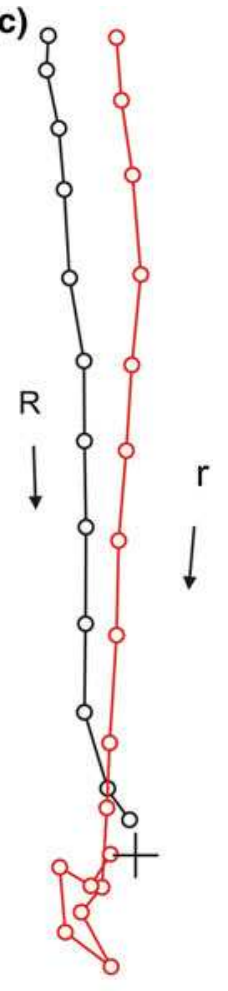

Fig. 8 Homeward trajectories of recruits. Shown are inbound runs of recruited ants $(r, r e d)$ relative to $\mathbf{a}$ the own outbound run and $\mathbf{b}$ to the outbound run as well as $\mathbf{c}$ the return run of the recruiter $(R$, black $)$. Dots and circles mark 10-sec intervals on outbound and return paths, respectively (arrows indicate the running direction). Crosses denote the position of the nest-entrance hole

temporal distribution as well as the characteristics of the food resources. Consequently, its various components are related more to ecological influences than to phylogenetic dependencies (Traniello 1989; Hölldobler and Wilson 1990). Thermophilic ants, which mainly search for dead arthropod matter, are solitary foragers par excellence being active at the hottest times of day when other ant species refrain from foraging (Cataglyphis: Harkness and Wehner 1977; Schmid-Hempel 1983; Wehner et al. 1992; Cerdá et al. 1998; Wehner and Wehner 2011; Ocymyrmex: Marsh 1985, 1988; Wehner 1987; Wehner and Wehner 2011; Melophorus: Christian and Morton 1992; Cheng et al. 2009). Decade-long field studies especially in Cataglyphis bicolor and C. fortis have never revealed any sign of chemical recruitment to a food site, even if at an artificial feeder food was presented ad libitum. Some intranidal activation can occur when a successful forager returns from a newly established rich food source, but in Cataglyphis such short-term increases in the number of nest-leaving foragers have no directional component (see also Szlep 1973). For example, in C. floricola, a species endemic to the southwest of the Iberian Peninsula and belonging to a phylogenetically rather ancestral Cataglyphis clade (Tinaut 
1993), nest mates can get alerted by an individual forager, which has found a piece of prey that is too heavy to be transported by herself and is located close $(<1 \mathrm{~m})$ to the nest entrance (Amor et al. 2010). After such a forager has returned to the colony, more ants than recorded in control observations leave the nest entrance and start to search in all directions in the immediate vicinity of the nest, but neither recruitment pheromones nor other forms of directional information are involved in this stimulation response.

In the recently discovered (and taxonomically not yet identified) Australian salt-lake species of Melophorus one instance has been described in which a scout ant having discovered a dead scorpion recruited a loose group of 12 nest mates over a distance of $17.2 \mathrm{~m}$ to the food item by dragging its gaster on the ground (Schultheiss et al. 2013). The recruits followed, often at a distance of several meters behind the leading ant, and along more tortuous paths, but finally all reached the goal. This episode is reminiscent of the recruitment behaviour dealt within the present account in Ocymyrmex.

Our results raise two kinds of questions: one aiming at the functional significance and the other at the behavioural mechanism of the observed recruitment events.

\section{Functional significance}

As thermophilic desert ants forage for isolated food items, there is usually no need for recruitment. However, depending on past experience about food availability, $C$. bicolor, C. fortis, and C. albicans develop rather strong sector fidelities (Schmid-Hempel 1983; Wehner et al. 1983, 2004; Wehner 1987), just as O. robustior does (Fig. 1). In Cataglyphis we have found that the higher the success rate, the more rigidly the foragers stick to a preferred foraging direction. But how persistently does a worker return to a previous finding site within her preferred foraging sector? In asking this question we propose the hypothesis that revisiting a former finding site and exploiting it repeatedly but individually is a first step in recruiting nest mates to that site and thus exploiting it collectively. In $C$. bicolor and $C$. fortis the tendency to re-search a former site increases with food-patch quality (Schmid-Hempel 1984), e.g., in the form of food-item density (Bolek et al. 2012), and spatial details of searching at a former site may even depend on the nutrient value of a renewable source (Melophorus bagoti, Schultheiss and Cheng 2012), but the tendency to evaluate and potentially revisit a lucrative site does not result in finally recruiting nest mates to that site.

In Ocymyrmex, however, the present study shows that recruitment to a rich food source is a rather common foraging trait, which rides on top of the predominantly solitary food-retrieval regime employed by these thermophilic scavengers in very much the same way as in Cataglyphis. At any one day the number of exits (nest-leaving events) of solitary foragers exceeds that of recruited ants by about two orders of magnitude. During 37 observation days a mean of 1.7 recruitments (range $0-7$ ) occurred per day (mean number of recruits per recruitment event, 3.2). In the North American honey ant Myrmecocystus mimicus, which forages extensively on termites and which recruits groups of up to 300 nest mates to sites where termites appear above ground (for recruitment mechanism, see below), such recruitment-based massive nest departures constitute a major fraction of the foraging activity of this species (Hölldobler 1981a). The significance of this recruitmentbased, often hours-long exploitation of termite food sources is further corroborated by the fact that the ants prevent neighbouring conspecific colonies from access to such sources by performing elaborate territorial tournament displays (Hölldobler 1981a). In contrast, and as mentioned above, in $O$. robustior recruitment to termite or other food sites occurs much less frequently and involves much smaller groups of ants than in the North American honey ants. It is fully outcompeted by the food intake rate due to the solitary mode of foraging.

As the age distribution of recruiters and recruits show, recruitment behaviour seems to be part of the ants' agerelated division-of-labour schedule. The recruiters are experienced foragers (12 foraging days old), on average 5 days older than the recruited ants that had already been engaged in solitary foraging before they participated in a recruitment event (experienced recruits), and by definition 12 days older than the recruited newcomers, which prior to their recruitment had not yet started their foraging lives (inexperienced recruits). The observation that the recruiters are considerably older than the recruits is in accord with observations made in Camponotus and Formica species, in which the active recruiters in nest-moving events belong to a cohort of older workers characterised by the most degenerated ovarioles (Otto 1958; Kneitz 1964; Möglich and Hölldobler 1974). This also conforms with what has been reported for the inter-nest carrying behaviour in the polydomous species Cataglyphis bicolor, in which the carrier ants belong to the oldest (forager) age class endowed with the smallest ovarioles, fat body and labial gland volumes (Wehner et al. 1972).

In the case of the potential newcomers ("inexperienced ants") a caveat must be added. We do not yet know the probability, as low as it might ever be, that a forager ceases foraging for the 3-day period during which all foragers had been marked (see "Methods"), or for even longer periods, before she continues foraging and re-appears, then as an unmarked individual, above ground. However, at a colony of Ocymyrmex velox, a species of the Namib gravel plains, the entire foraging force consisting of $40.5 \pm 3.3$ 
individuals being active per day had been marked individually for several weeks. In this case the majority of recruits were indeed newcomers and started their individual foraging only 1-3 days after they had been recruited to a termite site (Wehner 1987). In emigration events of nomadic army ants, Neivamyrmex nigrescens, newly emerged callows join the other colony members in travelling along chemical trails, while they start foraging only 3-7 days later (Topoff et al. 1972).

Foragers of Cataglyphis bicolor re-search a previous finding site the more persistently, the farther that site is from the nest (Schmid-Hempel 1984) and hence, as we can now add, the higher the foraging age of an ant is (Wehner et al. 2004). In Ocymyrmex our present results show that the recruiters belong to the oldest age group of foragers as well. This line of arguments supports our previous hypothesis (see above) that the persistency to return to a lucrative feeding site is a first step towards recruiting nest mates to that site. Seen in this light, ants of the genus Cataglyphis would not have taken-or, better yet, would have abandoned - the second step. This leaves us with the overarching question why Ocymymrex ants do recruit, while Cataglyphis ants do not. Is this difference between the two genera of thermophilic ants due to recent ecological (e.g., dietary) factors or a result of evolutionary history? In any way, the strong dichotomy stating that species foraging at lower temperatures employ group recruitment, and those foraging at higher temperatures-especially thermophilic species-do not (Ruano et al. 2000), obviously overemphasises a general trend. In fact, the surface temperatures at which $O$. robustior and $O$. velox employed group recruitment (most likely by depositing pheromone signposts, see below) were considerably higher than the ones at which recruitment did not occur in the Cataglyphis species tested in this respect.

\section{Behavioural mechanisms}

We owe it mainly to Bert Hölldobler that we now have a rather full appreciation of the plethora of chemical recruitment systems that have evolved in ants (Hölldobler 1981b; Hölldobler and Wilson 2009). The kind of recruitment observed in $O$. robustior seems to come closest to what has been described for Camponotus socius (Hölldobler 1971) and M. mimicus (Hölldobler 1981a). In C. socius a scout having discovered a lucrative food source lays a hindgut-pheromone trail from the source back to the nest. This trail does not induce recruitment by itself, but serves as an orientation cue. Inside the nest the recruiting ant performs characteristic waggle displays, which alert nest mates to get recruited. Finally, a group of 2-30 ants appears above ground and follows closely behind the leading ant, the recruiter. During this process the highly volatile formic acid discharged by the recruiter from the poison gland serves as the recruiting signal (Kohl et al. 2001). This behaviour, which has also been observed in some other Camponotus species (Hölldobler 1982; Kohl et al. 2003) and, for example, in several species of Polyrhachis (Liefke et al. 2001), is regarded as one of the most original kinds of group recruitment strategies (Hölldobler and Wilson 1990). In M. mimicus a scout ant returning from an active termite site lays a chemical trail by touching the ground with her abdominal tip. Upon arrival at the nest, she contacts a number of nest mates, which are already outside the nest entrance, by performing rapid jerky display movements, and then leaves the nest again in the direction of the food source. While repeatedly touching the ground with the tip of her gaster (as done on the preceding return form the newly discovered source) she is now followed by a large group of 20-300 ants (Hölldobler 1981a).

Of course, as we have not yet isolated trail pheromones from the ants' exocrine glands and directly tested their effects (for a preliminary test, see artificial-trail experiment above), the involvement of such substances in the group recruitment behaviour of $O$. robustior can only be proposed as a hypothesis, though a most likely one. First, in all ants studied so far in similar situations (see above) the behaviour of the recruiter to tip down her gaster to the surface of the ground has invariably been associated with the deposition of chemical signposts. For example, when Hölldobler (1971) described this behaviour in Camponotus socius, his Fig. 7 showing a small group of recruits following the recruiter at some distance corresponds in nearly every respect with Fig. 7 in the present account. Second, in some kind of counter hypothesis one could assume that the recruits perceived the recruiter's tip-down movement of the gaster visually. However, this is very unlikely indeed, because the optical resolution of the ants' eyes would make any perception of changes in the recruiter's body posture from the distances at which the recruits respond (Fig. 6) well-nigh impossible (see optical measurements and computations on the compound eyes of several Cataglyphis species in Zollikofer et al. 1995; moreover, O. robustior possesses only about 500 ommatidia per eye, i.e., only half the number of ommatidia present in a medium-sized $C$. bicolor). Furthermore, in the gravel plain desert, in which group recruitment has been observed first (in $O$. velox, see above), any visually guided pursuit behaviour would be impeded even more. Hence, in the following discussion we assume that the chemical-signpost hypothesis describes what actually occurs in $O$. robustior.

In comparing the recruitment system of $O$. robustior with that of $C$. socius and M. mimicus we must first mention that we have never observed trail laying behaviour of ants returning from our newly established experimental food sites to which recruitment later occurred. Moreover, 
given the high velocity with which the leading ant finally hurries off towards the former finding site, we consider it unlikely that a previously laid pheromone trail is used for guidance. Furthermore, as the recruiters belong to the oldest age group of foragers and thus have already developed strong sector fidelities, they might easily find their way back to the food source by employing their path integration food vector (Collett et al. 1999; Wehner et al. 2002) or other visually mediated navigational routines. Furthermore, it is also the recruits that do not seem to follow a long-lasting orientation trail. In trying to keep up with the leader, which is assumed to intermittently deposit an obviously highly volatile chemical signpost on the surface of the ground, they perform rapid looping and zigzagging movements and often get lost. In C. socius, the recruits move much more slowly and follow the leader much more directly than what we observe in O. robustior. In the latter species the behaviour resembles in several respects that of male moths flying upwind (Baker and Vickers 1997; Cardé and Mafra-Neto 1997; Cardé and Willis 2008) or male cockroaches walking upwind (Tobin 1981; Willis and Avondet 2005; Willis et al. 2011) within a female pheromone plume rather than that of typical trail following in ants.

As the leader always moves directly, along a more or less straight path, towards the goal, and as the recruits often overtake the leader, it is a likely hypothesis that the recruited ants rely, at least for certain periods of time, on their path integration system to advance towards the unknown goal by moving in, and undulating about, the counter direction of their current home vector once an odour signal has been detected during the ongoing recruitment process. They may do so until a few moments later the leader has proceeded further and the recruits can again pick up the decisive signal. In general, the high-speed movements of $O$. robustior in open sandflat terrain might have favoured the employment of the path integration system in many aspects of the recruitment process. Especially in returning to their home base, the nest, neither recruiters nor recruits seem to depend on chemical markers. The homing recruiters and recruits do not retrace their outbound paths, nor do the recruits follow the outbound or inbound paths of the recruiter. Of course, displacement experiments must provide the final proof. Furthermore, there is a high probability that the unmarked recruits have been newcomers, that is, ants that prior to their recruitment had not yet started their foraging lives. As the accuracy of their homebound runs is statistically indistinguishable from that of experienced recruits (and that of the recruiters), our results would then lend support to the generally held (e.g., Graham 2010), though not yet fully substantiated view that path integration is an inborn navigational routine operating already during the ants' first foraging runs (for some indications that this might be the case, see Wehner 2012).

In any way, the recruitment phenomenon described here in $O$. robustior might well provide an opportunity to study the interplay of orientation by chemical signposts and path integration as well as other visual guidance mechanisms in both recruiters and recruits. For example, as hypothesised above, if a recruit loses contact with the odour signal, the $180^{\circ}$ counter direction of its current path integration vector might provide an at least short-term directional cue, just as wind direction does in anemotactic upwind orientation. In this context, it is a likely hypothesis that in the thermophilic $O$. robustior the path integration vector-that is, the home vector and its $180^{\circ}$ counter direction-may play the role of the long-lasting chemical orientation cues employed in the group recruitment process described for the Camponotus species mentioned above.

Acknowledgments We thank Christine Gutzwiller and Sibylle Wehner for their cooperation during various stages of the experiments, Joh Henschel, Thomas Nørgaard, and the staff of the Gobabeb Training and Research Centre, Namibia, for infrastructural help in various ways, Bert Hölldobler for helpful comments on Myrmecocystus mimicus, Steffen Pielström for providing us with video sequences of the recruitment behaviour of Camponotus socius, and two reviewers for helpful comments. Financial support came from the Swiss National Science Foundation (Grant no. 31-61844.00 to RW) and the Deutsche Forschungsgemeinschaft (Grant no. 3675/1-1 and Grant no. SFB 554 A8 to RW and WR, respectively). The experiments comply with the current law of the country in which they were performed.

Conflict of interest The authors declare that they have no conflict of interest.

\section{References}

Amor F, Ortega P, Cerdá X, Boulay R (2010) Cooperative preyretrieving in the ant Cataglyphis floricola: an unusual shortdistance recruitment. Insectes Soc 57:91-94

Baker TC, Vickers NJ (1997) Pheromone-mediated flight in moths. In: Cardé RT, Minks AK (eds) Insect pheromone research. New directions. Chapman and Hall, New York, pp 248-264

Batschelet E (1981) Circular statistics in biology. Academic Press, London

Bolek S, Wittlinger M, Wolf H (2012) What counts for ants? How return behaviour and food search of Cataglyphis ants are modified by variations in food quantity and experience. J Exp Biol 215:3218-3222

Cardé RT, Mafra-Neto A (1997) Mechanisms of flight of male moths to pheromone. In: Cardé RT, Minks AK (eds) Insect pheromone research. New directions. Chapman and Hall, New York, pp 275-290

Cardé RT, Willis MA (2008) Navigational strategies used by insects to find distant, wind-borne sources of odor. J Chem Ecol 34:854-866

Cerdá X, Retana J, Manzaneda A (1998) The role of competition by dominants and temperature in the foraging of subordinate 
species in Mediterranean ant communities. Oecologia 117:404412

Cheng K, Narendra A, Sommer S, Wehner R (2009) Traveling in clutter: navigation in the central Australian desert ant Melophorus bagoti. Behav Processes 80:261-268

Christian KA, Morton SR (1992) Extreme thermophilia in a central Australian ant, Melophorus bagoti. Physiol Zool 65:885-905

Clark PJ, Evans FC (1954) Distance to nearest neighbor as a measure of spatial relationships in populations. Ecology 35:445-453

Collett M, Collett TS, Wehner R (1999) Calibration of vector navigation in desert ants. Curr Biol 9:1031-1034

Graham P (2010) Insect navigation. In: Breed MD, Moore J (eds) Encyclopedia of animal behavior, vol 2. Academic Press, Oxford, pp 167-175

Harkness R, Wehner R (1977) Cataglyphis. Endeavour NS 1:115-121

Hölldobler B (1971) Recruitment behavior in Camponotus socius (Hym. Formicidae). Z vergl Physiol 75:123-142

Hölldobler B (1981a) Foraging and spatiotemporal territories in the honey ant Myrmecocystus mimicus (Hymenoptera: Formicidae). Behav Ecol Sociobiol 9:301-314

Hölldobler B (1981b) Zur Evolution von Rekrutierungssignalen bei Ameisen. Nova Acta Leopoldina N.F 54:431-447

Hölldobler B (1982) The cloacal gland, a new pheromone gland in ants. Naturwissenschaften 69:186-187

Hölldobler B (1984) Evolution of insect communication. Symp R Ent Soc 12:349-377

Hölldobler B, Lumsden CJ (1980) Territorial strategies in ants. Science 210:732-739

Hölldobler B, Wilson EO (1990) The ants. The Belknap Press of Harvard University Press, Cambridge

Hölldobler B, Wilson EO (2009) The superorganism: the beauty, elegance and strangeness of insect societies. W. W. Norton \& Company, New York

Kneitz G (1964) Saisonales trageverhalten bei Formica polyctena Foerst. (Formicidae, Gen. Formica). Insect Soc 11:105-129

Kohl E, Hölldobler B, Bestmann HJ (2001) Trail and recruitment pheromones in Camponotus socius (Hymenoptera: Formicidae). Chemoecology 11:67-73

Kohl E, Hölldobler B, Bestmann HJ (2003) Trail pheromones and Dufour gland contents in three Camponotus species (C. castaneus, C. balzani, C. sericeiventris: Formicidae, Hymenoptera). Chemoecology 13:113-122

Lenoir A, Nowbahari E, Quérard L, Pondicq N, Delalande C (1990) Habitat exploitation and intercolonial relationships in the ant Cataglyphis cursor (Hymenoptera, Formicidae). Acta Oecolol $11: 3-18$

Liefke C, Hölldobler B, Maschwitz U (2001) Recruitment behavior in the ant genus Polyrhachis (Hymenoptera, Formicidae). J Insect Behav 14:637-657

Marsh AC (1985) Microclimatic factors influencing foraging patterns and success of the thermophilic desert ant, Ocymyrmex barbiger. Insectes Soc 32:286-296

Marsh AC (1988) Activity patterns of some Namib Desert ants. J Arid Environ 14:61-73

Mizuno K (2010) Environmental change and vegetation succession along an ephemeral river: the Kuiseb in the Namib. Afr Study Monogr Suppl 40:3-18

Möglich M, Hölldobler B (1974) Social carrying behavior and division of labor during nest moving in ants. Psyche 81:219-236

Muser B, Sommer S, Wolf H, Wehner R (2005) Foraging ecology of the thermophilic Australian desert ant, Melophorus bagoti. Austr J Zool 53:301-311

Otto D (1958) Über die Arbeitsteilung im Staate von Formica rufa rufo-pratensis minor und ihrer verhaltensphysiologischen Grundlagen: ein Beitrag zur Biologie der Roten Waldameise. Wiss Abh Dtsch Akad Landwirtsch Wiss Berlin 30:1-169
Ruano F, Tinaut A, Soler JJ (2000) High surface temperatures select for individual foraging in ants. Behav Ecol 11:396-404

Schachtschneider K, February EC (2010) The relationship between fog, floods, groundwater and tree growth along the lower Kuiseb River in the hyperarid Namib. J Arid Environ 74:1632-1637

Schmid-Hempel P (1983) Foraging ecology and colony structure of two sympatric species of desert ants Cataglyphis bicolor and Cataglyphis albicans. Dissertation, University of Zürich

Schmid-Hempel P (1984) Individually different foraging methods in the desert ant Cataglyphis bicolor (Hymenoptera, Formicidae). Behav Ecol Sociobiol 14:263-271

Schultheiss P, Cheng K (2012) Finding food: outbound searching behavior in the Australian desert ant Melophorus bagoti. Behav Ecol 24:128-135

Schultheiss P, Schwarz S, Cheng K, Wehner R (2013) Foraging ecology of an Australian salt-pan desert ant (genus Melophorus). Austr J Zool 60:311-319

Szlep R (1973) Motor display as a means of recruitment to food sources in ants. Proc Congr Int Union Stud Soc Ins 7:383-384

Theron GK, van Rooyen N, van Rooyen MW (1980) Vegetation of the lower Kuiseb River. Modoqua 11:327-345

Tinaut A (1993) Cataglyphis floricola $\mathrm{n}$. sp. new species for the genus Cataglyphis Förster, 1850 (Hymenoptera, Formicidae) in the Iberian Peninsula. Mitt Schweiz Entomol Ges 66:123-134

Tobin TR (1981) Pheromone orientation: role of internal control mechanisms. Science 214:1147-1149

Topoff H, Boshes N, Trakimas W (1972) A comparison of trail following between callow and adult workers of the army ant [Neivamyrmex nigrescens (Formicidae: Dorylinae)]. Anim Behav 20:361-366

Traniello JFA (1989) Foraging strategies of ants. Ann Rev Entomol 34:191-210

Vander Meer RK (1986) The trail pheromone complex of Solenopsis invicta and Solenopsis richteri. In: Lofgren CS, Vander Meer RK (eds) Fire ants and leaf-cutting ants: biology and management. Westview Press, Boulder, pp 201-210

Wehner R (1987) Spatial organization of foraging behaviour in individually searching desert ants, Cataglyphis (Sahara Desert) and Ocymyrmex (Namib Desert). In: Pasteels JM, Deneubourg J-L (eds) From individual to collective behaviour in social insects. Birkhäuser, Basel, pp 15-42

Wehner R (2012) Wüstennavigatoren en miniature. Biol unserer Zeit 42:364-373

Wehner R, Wehner S (2011) Parallel evolution of thermophilia: daily and seasonal foraging patterns of heat-adapted desert ants: Cataglyphis and Ocymyrmex species. Physiol Entomol 36: 271-281

Wehner R, Herrling PL, Brunnert A, Klein R (1972) Periphere adaptation und zentralnervöse Umstimmung im optischen System von Cataglyphis bicolor (Formicidae, Hymsnoptera). Rev Suisse Zool 77:239-255

Wehner R, Harkness RD, Schmid-Hempel P (1983) Foraging strategies in individually searching ants, Cataglyphis bicolor (Hymenoptera: Formicidae). Akademie der Wissenschaften und der Literatur and Fischer Verlag, Mainz and Stuttgart

Wehner R, Marsh AC, Wehner S (1992) Desert ants on a thermal tightrope. Nature 357:586-587

Wehner R, Gallizzi K, Frei C, Vesely M (2002) Calibration processes in desert ant navigation: vector courses and systematic search. J Comp Physiol A 188:683-693

Wehner R, Meier C, Zollikofer C (2004) The ontogeny of foraging behaviour in desert ants, Cataglyphis bicolor. Ecol Entomol 29:240-250

Willis MA, Avondet JL (2005) Odor-mediated orientation in walking male cockroaches Periplaneta americana, and the effects of odor plumes of different structure. J Exp Biol 208:721-735 
Willis MA, Avondet JL, Zheng E (2011) The role of vision in odorplume tracking by walking and flying insects. J Exp Biol 214:4121-4132

Wilson EO (1962) Chemical communication among workers of the fire ant Solenopsis saevissima (Fr. Smith). 1. The organization of mass-foraging. 2. An information analysis of the odour trail. 3. The experimental induction of social responses. Anim Behav 10:134-164

Zollikofer CPE, Wehner R, Fukushi T (1995) Optical scaling in conspecific Cataglyphis ants. J Exp Biol 198:1637-1646 